International Journal of Engineering \& Technology, $7(4.20)(2018) 108-112$
SPC
SPebsite: www.sciencepubco.com/index.php/IJET
Research paper

\title{
Experimental Investigation of Thermal Response of Encased Composite Beams
}

\author{
Sallal R. Abid ${ }^{* 1}$, Faten I. Mussa ${ }^{2}$, Nildem Tayşi ${ }^{3}$ \\ ${ }^{1}$ Civil Engineering Department, College of Engineering, Wasit University, Iraq \\ ${ }^{2}$ Civil Engineering Department, College of Engineering, Misan University, Iraq \\ ${ }^{3}$ Civil Engineering Department, College of Engineering, Gaziantep University, Turkey \\ *Corresponding author E-mail: sallal@uowasit.edu.iq
}

\begin{abstract}
Many types of structures, or part of which, are directly under the exposure of the time-dependent variations of the temperature of air and solar radiation. Such thermal loads can vary the temperature of the different parts of the structural members causing undesired structural effects. In this research, an experimental study was conducted to investigate the influence of such thermal loads on composite beams. For this purpose, a concrete-encased-steel beam was instrumented with fifteen thermocouples and other sensors. The records were captured for a sunny winter day with moderately high daily air temperature difference of more than $18{ }^{\circ} \mathrm{C}$ and a solar radiation of more than $700 \mathrm{~W} / \mathrm{m}^{2}$. The results showed that the hourly temperature variation and the sun movement in addition to the altitude angle of sun rays control the vertical and lateral temperature distributions of the beam. The maximum recorded difference between hourly maximum and minimum temperatures of the beam was $12.5^{\circ} \mathrm{C}$.
\end{abstract}

Keywords: air temperature; composite beam; concrete-encased-steel; solar radiation; temperature distribution.

\section{Introduction}

Structures differ among each other according to their function, and accordingly, the structure should be designed to safely and adequately withstand the different types of applied loads. Typically, concrete, steel, or composite structures are designed to resist gravity dead and live loads and if required lateral seismic and wind loads. Special function structures are designed to accommodate additional types of loads to fulfill the requirements of their function. Some structures are designed to resist the thermal actions arise from the fluctuation of the atmospheric loads that influence the temperature of its members. The best example of such type of structures is bridges, where most of the superstructure is under continuous influence of the daily fluctuation of the atmospheric thermal loads. The most important and most effective of the atmospheric thermal loads are the air temperature and solar radiation [1-2].

Previous researches showed that such thermal loads can cause serious undesirable effects like concrete cracking [1]. Several experimental researches were conducted to evaluate the thermal response of concrete beams [2-8], while other experimental researches were directed to study these effects on steel beams [9-11]. However, the experimental researches that investigate the effect of the atmospheric thermal loads on composite beams are few in the literature [12]. In this research, an experimental concrete-encased-steel composite beam was constructed in an open environment to study the thermal response of such type of beams under the atmospheric thermal loads. The beam was instrumented with fifteen thermocouple and other different sensors. The experimental results presented in this research can very helpful as a verification tool for numerical investigations on structures including composite steel-concrete sections.

\section{Experimental work}

The experimental setup of this study includes the fabrication and casting of a composite test specimen at the campus of Gaziantep University/Turkey. This specimen is a concrete-encased-steel beam segment, which composes of an I-shape steel beam segment embedded inside an I-shape concrete beam. The steel beam has a web depth of $400 \mathrm{~mm}$, which was welded to two flanges with width of $200 \mathrm{~mm}$. The thickness the web and flanges is $8 \mathrm{~mm}$. On the other hand, the concrete beam has a web and flanges thickness of $100 \mathrm{~mm}$, while the total depth of the beam is $500 \mathrm{~mm}$. The width of the top and bottom flanges of the concrete beam are 800 and $300 \mathrm{~mm}$, respectively, while the length of the composite beam segment is 500 $\mathrm{mm}$. The dimensions of the experimental girder segment are shown in Fig. 1. The top flange of the concrete beam was reinforced with a two-way grid of $10 \mathrm{~mm}$ diameter reinforcing bars as shown in Fig. 2(a). The beam was instrumented with 15 thermocouples distributed at different locations in the concrete beam and on the steel section. If the $(0,0)$ coordinates are considered to be at the center of the bottom surface of the bottom flange of the composite section, then the lateral (x) and vertical (y) coordinates of the concrete and steel thermocouples are listed in Tables 1 and 2, respectively. Note that all thermocouples were installed along the mid-span section of the beam as shown in Fig. 2(a). The thermocouple wires were then grouped as shown in Fig. 2(b) and connected to the data acquisition system. To simultaneously measure the solar radiation intensity, a silicon pyranometer was installed at the same experimental field next to the composite beam. Similarly, air temperature sensor and wind speed anemometer were installed and all were connected to 
the data acquisition system to have simultaneous records. The output data were collected and tabulated in excel sheet by the software of the data logger 48 times a day, hence, at time steps of 30 minutes.

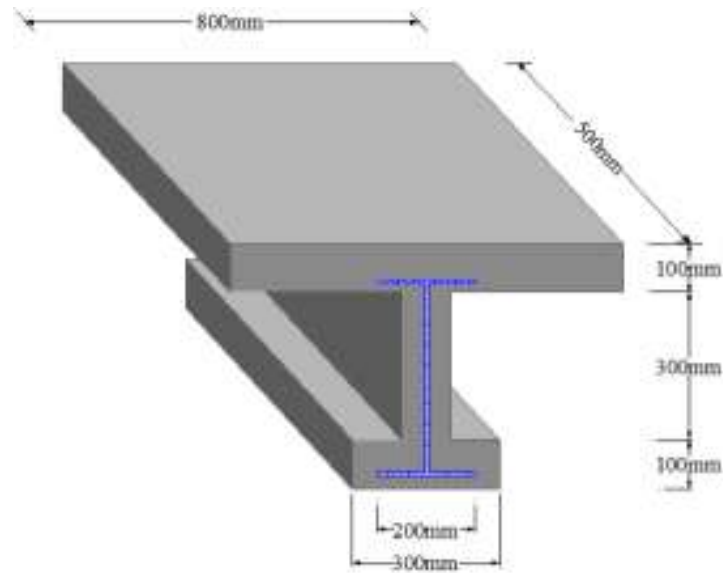

Fig 1: Geometry of the experimental composite girder

Table 1: The coordinates of the concrete thermocouples

\begin{tabular}{|c|c|c|c|c|c|}
\hline $\mathrm{TC}$ & $\begin{array}{c}\mathrm{X} \\
(\mathrm{mm})\end{array}$ & $\begin{array}{c}\mathrm{y} \\
(\mathrm{mm})\end{array}$ & TC & $\begin{array}{c}\mathrm{X} \\
(\mathrm{mm})\end{array}$ & $\begin{array}{c}\mathrm{y} \\
(\mathrm{mm})\end{array}$ \\
\hline \multicolumn{3}{|c|}{$\begin{array}{l}\text { Concrete Vertical } \\
\text { Thermocouples }\end{array}$} & \multicolumn{3}{|c|}{$\begin{array}{l}\text { Top Flange Lateral } \\
\text { Thermocouples }\end{array}$} \\
\hline TC1 & 0 & 500 & TC4 & -400 & 450 \\
\hline TC2 & 0 & 475 & TC5 & -200 & 450 \\
\hline TC3 & 0 & 450 & TC6 & 200 & 450 \\
\hline TC10 & 0 & 0 & TC7 & 400 & 450 \\
\hline \multicolumn{3}{|c|}{$\begin{array}{c}\text { Bottom Flange Lateral } \\
\text { Thermocouples }\end{array}$} & \multicolumn{3}{|c|}{$\begin{array}{l}\text { Web Lateral } \\
\text { Thermocouples }\end{array}$} \\
\hline TC8 & -150 & 50 & TC11 & -50 & 250 \\
\hline TC9 & 150 & 50 & TC12 & 50 & 250 \\
\hline
\end{tabular}

Table 2: The coordinates of the steel thermocouples

\begin{tabular}{|c|c|c|}
\hline Thermocouple & $\begin{array}{c}\mathrm{x} \\
(\mathrm{mm})\end{array}$ & $\begin{array}{c}\mathrm{y} \\
(\mathrm{mm})\end{array}$ \\
\hline TS1 & 425 & 0 \\
\hline TS2 & 250 & -4 \\
\hline TS3 & 25 & 0 \\
\hline
\end{tabular}

The temperature, solar radiation, and wind speed recording continued for approximately two months during the winter season. However, among the accumulated data, the records of only one day were chosen for presentation to optimize the results and discussion section. A sunny day (18-February-2015) with daily maximum hourly solar radiation of $712 \mathrm{~W} / \mathrm{m}^{2}$ and a daily air temperature difference of $18.5^{\circ} \mathrm{C}$ was selected for this mission. The daily maximum and minimum air temperatures of this day were 23 and $4.5^{\circ} \mathrm{C}$, respectively, while its daily average wind speed was $0.44 \mathrm{~m} / \mathrm{s}$. Fig. 3 shows the distributions of solar radiation and air temperature during the 24 hours of the selected day, while Fig. 4 shows the hourly variation of wind speed of this day.

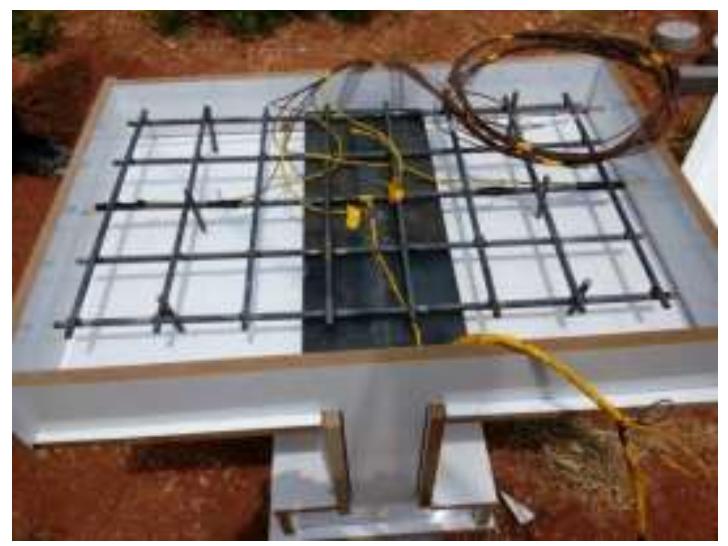

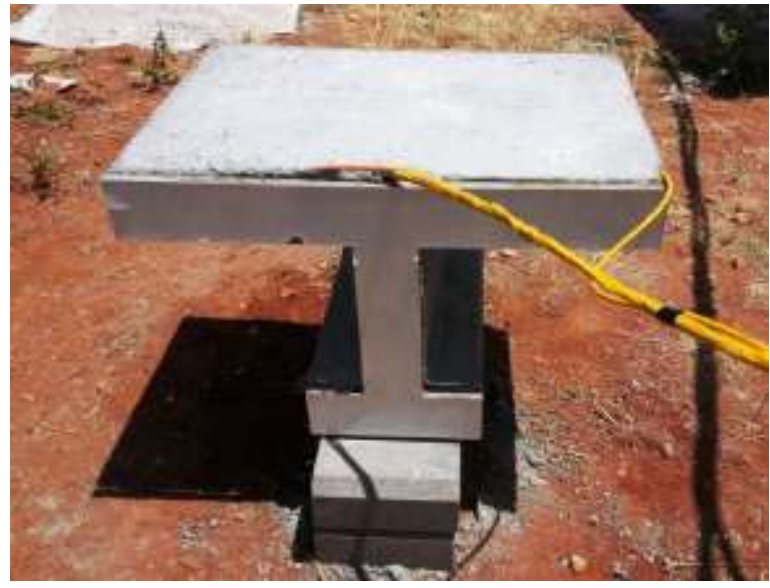

Fig. 2: The experimental girder segment (a) The formwork and the installation of the thermocouples, (b) the final view

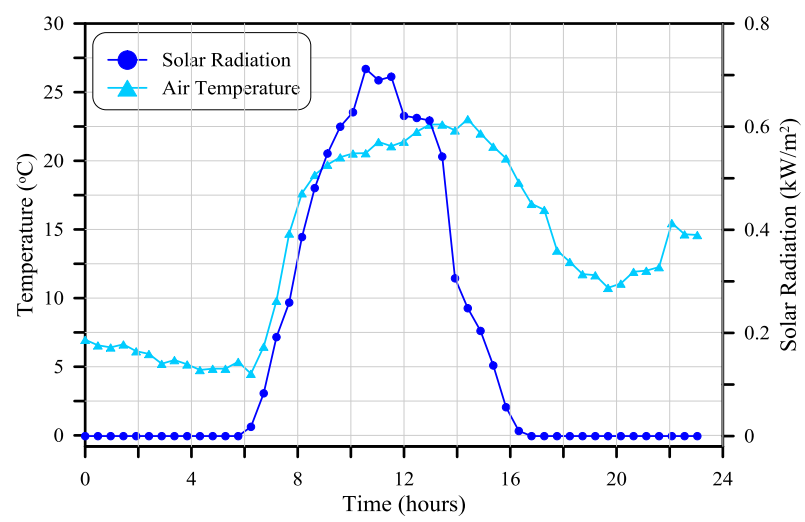

Fig. 3: Hourly distribution of solar radiation and air temperature

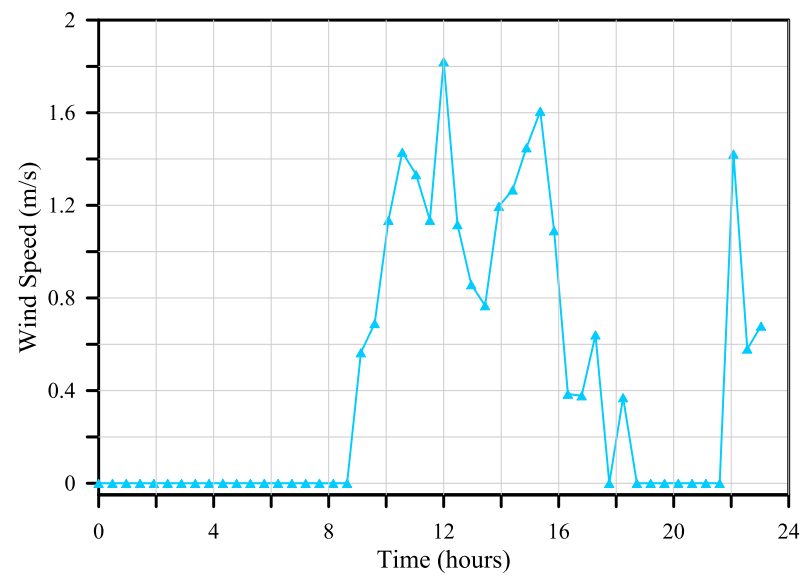

Fig.4: Hourly distribution of wind speed

\section{Hourly variation of thermocouple tempera- tures}

Figs. 5 to 10 present the 24-hour variation of temperature for groups of thermocouples along or across a specific member of the composite beam. The presented groups were selected because they can support a better understanding of temperature variations along or across the members of the composite beam, which in turn control the thermal strains and stresses there.

Fig. 5 shows the variation of the thermocouples TC1, TC2, and TC3 with time. These thermocouples are installed across the thickness of the top flange, at its central with. TC1 is installed directly beneath the top surface, while TC2 and TC3 are installed at 25 and $50 \mathrm{~mm}$ below TC1, respectively. Fig. 5 shows that TC1 exhibits the highest daily temperatures and the lowest night temperatures among the three thermocouples, while the deepest thermocouple TC3 exhibits 
the opposite behavior. This result is an expected one as TC1 is the top surface thermocouple. Thus, it is subjected directly to the day rise and night drop of air temperature and also to the direct effect of solar radiation. This leads to the increase of its temperature during the heating hours (day hours) and the decrease of its temperature during the cooling hours (night hours) compared to the interior thermocouples. The interior thermocouples (TC2 and TC3) receive the conducted heat from the top surface. As concrete thermal conductivity is weak, this heat would necessarily be lower than that received by the surface thermocouple $\mathrm{TC} 1$, and its lower for the deeper thermocouple (TC3) than TC2. During the night hours, the surface thermocouple (TC1) loses its temperature rapidly under the effect of convection cooling, while deeper thermocouples slowly dissipate their reserved heat via conduction. The surface long wave radiation also participate the cooling process of the beam. The daily maximum temperatures of TC1, TC2, and TC 3 were $31.3,30.2$, and $28.9^{\circ} \mathrm{C}$, respectively, while their minimums were close and were $18.8,18.4$, and $18.1{ }^{\circ} \mathrm{C}$, respectively. It can be noted that the variation between the three thermocouple still somewhat small. This can be attributed to two reasons. The first is that the weather conditions are winter conditions with low daily maximum air temperature and low solar radiation, while the second reason is that the distance between each of the three thermocouples is only $25 \mathrm{~mm}$.

Fig. 6 shows the vertical variation of temperature along the vertical centerline of the beam, where TC1 is the top surface thermocouple, TC10 is the bottom surface thermocouple, and TS2 is the central depth steel thermocouple. The figure also shows the distinguishable higher daily maximum temperature of $\mathrm{TC} 1$, which was discussed above. The noticeably lower temperature of TC10 can be attributed to the low amount of reflected radiation received by the bottom surface of the beam. On the other hand, it can be noticed that the central thermocouple TS2 show slightly higher day-temperatures than the bottom surface one. This is because TS2 receives higher conducted solar energy than the reflected solar energy received by TC10, which is attributed to the low inclination angles of solar radiations during winter. Hence, vertical surfaces in winter receive higher intensities of solar radiations that horizontal surfaces. The recorded daily maximum temperatures of TC10 and TS2 were 25.9 and 26.4 ${ }^{\circ} \mathrm{C}$, respectively.

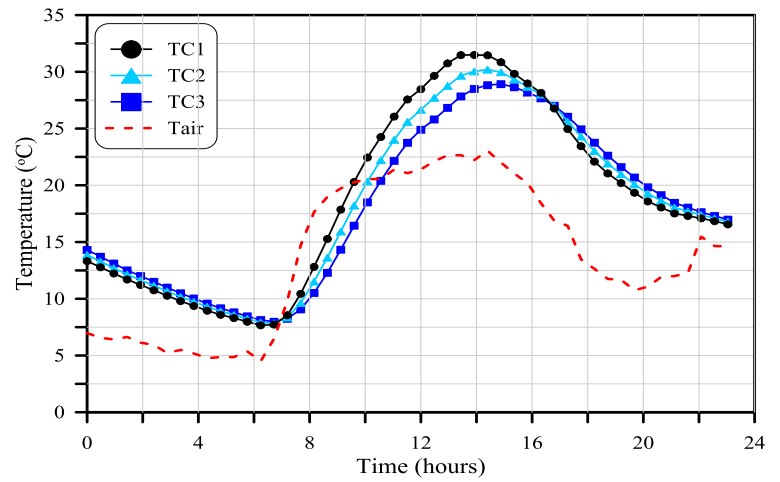

Fig. 5: Hourly temperatures of thermocouples TC1, TC2, TC3, and Tair

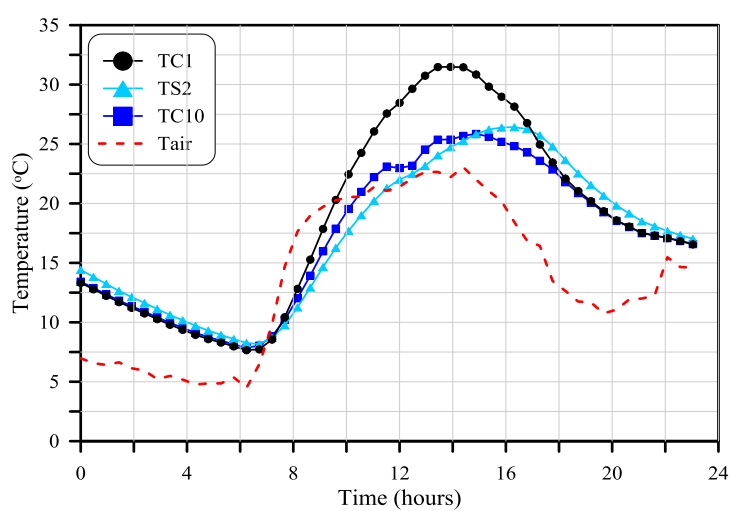

Fig. 6: Hourly temperatures of thermocouples TC1, TS2, TC10, and Tair
Fig. 7 shows the variation of thermocouples installed along the horizontal centerline of the top flange, these thermocouples with thermocouple TC 2 can be used to construct the lateral temperature gradient and hence thermal strain distributions there. The negative sign in Table 1 refers to the south direction, which means that the sequence of thermocouples TC4 to TC7 is from the southern edge of the top flange to its northern edge. This explains the higher temperatures of TC4 compared to the other thermocouples and similarly the lower temperatures of TC7 compared to the other thermocouples. As the sun moves from sunrise to sunset completely to the south of the equator with low inclination angles, then southern edges receive the greatest amount of solar energy. This amount is even higher than that received by the top surface of the beam, which again explains why the maximum temperature of TC4 is even higher than that of the top surface thermocouple TC1. The maximum recorded temperatures of TC4, TC5, TC6, and TC7 were 36.5, $30.8,30.3$, and $28.3{ }^{\circ} \mathrm{C}$, respectively, while that of TC1 was 31.5 ${ }^{\circ} \mathrm{C}$. For the same reason it can be seen in Fig. 8 that the temperature of the thermocouple TC8, which is installed on the southern edge of the bottom flange, is higher than that of TC9, which is installed on the northern edge of the bottom flange. Similarly, across the central section of the web as shown in Fig. 9, the temperature of the southern thermocouple TC11 was higher than that of the northern one TC12. The low differences between the temperatures of the steel thermocouples shown in Fig. 10 can be attributed to their location as they are embedded at a distance not less than $25 \mathrm{~mm}$ from the closet surface.

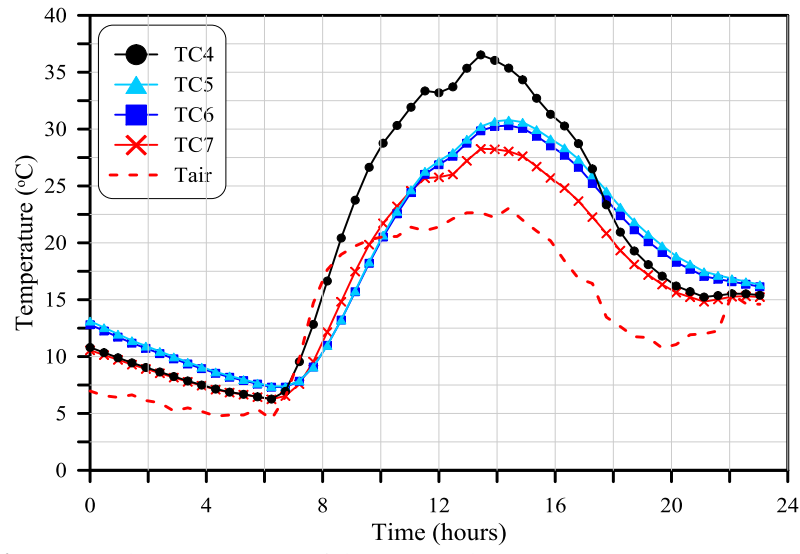

Fig. 7: Hourly temperatures of thermocouples TC4, TC5, TC6, TC7, and Tair

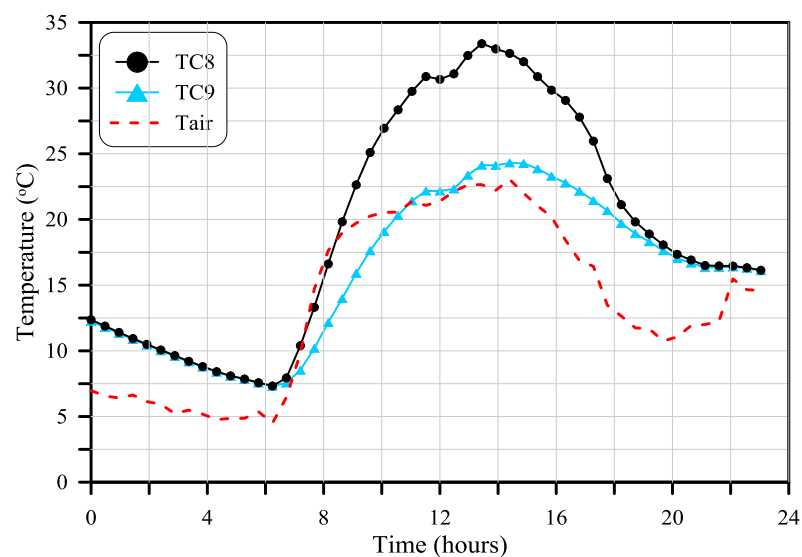

Fig. 8: Hourly temperatures of thermocouples TC8 and TC9 


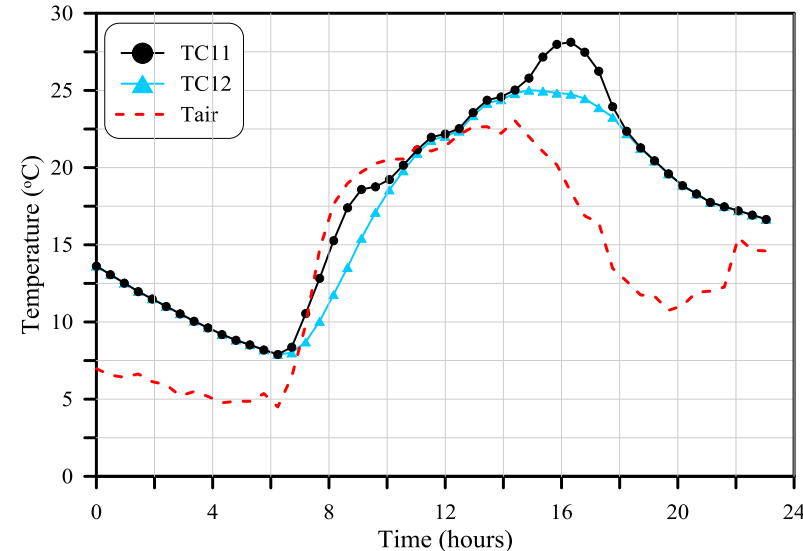

Fig. 9: Hourly temperatures of thermocouples TC11, TC12, and Tair

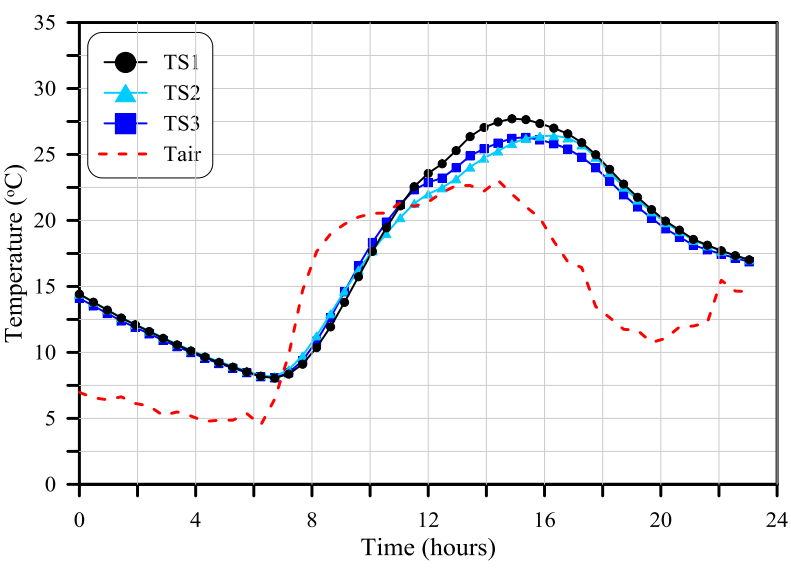

Fig. 10: Hourly temperatures of thermocouples TS1, TS2, TS3, and Tair

\section{Maximum, minimum, and average temper- atures}

It is shown in Fig. 11 that the fluctuation behaviors of the maximum and minimum temperatures of the beam are of similar trend to that of air temperature. The variation of the difference between the hourly maximum and minimum temperatures is of course affected by those of the maximum and minimum temperatures as obviously shown in Fig. 11. The difference between the hourly maximum and minimum temperatures of the beam was considered because it can give an image of the expected thermal strains due to solar radiation and air temperature variation. The daily maximum and minimum values of the hourly maximum beam temperature were recorded as 36.5 and $8.3{ }^{\circ} \mathrm{C}$, while the corresponding values of the beam hourly minimum temperature were 24.3 and $6.3{ }^{\circ} \mathrm{C}$. On the other, the hourly difference between the maximum and minimum temperatures was in the range of 1.8 and $12.5^{\circ} \mathrm{C}$, which reflects the possible ranges of temperature gradients across the section of the composite beam during the investigated day.

Fig. 12 shows the variation of the average temperatures with time. The figure presents the averages of the twelve concrete thermocouples, the three steel thermocouples, and the fifteen thermocouples. It is obvious that the average temperatures of the concrete thermocouples are higher than those of the steel thermocouples during the day hours. This is an expected result as some of these thermocouples are surface ones where the highest temperatures were recorded, while all of the steel thermocouples are interior ones. Another notice is that the average of all thermocouples is much closer to that of concrete than that of steel thermocouples. This can be attributed to the larger number of concrete thermocouples which is four times that of steel thermocouples. The average of the concrete thermocouples was in the range of 7.4 to $29^{\circ} \mathrm{C}$, while it was from 8.1 to $26.7^{\circ} \mathrm{C}$ for the steel thermocouples. The average of the fifteen thermocouples of the composite beam was recorded to be from 7.6 to $28.4^{\circ} \mathrm{C}$.

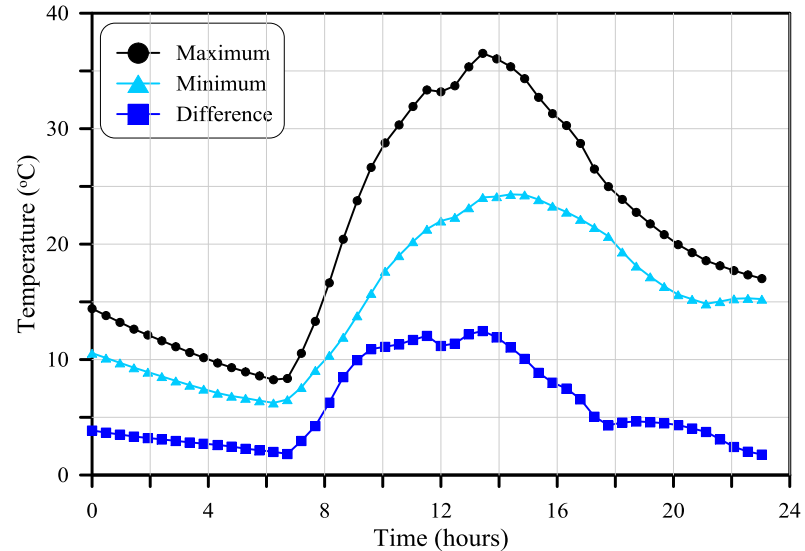

Fig. 11: Hourly maximum and minimum temperatures and hourly difference between maximum and minimum temperatures

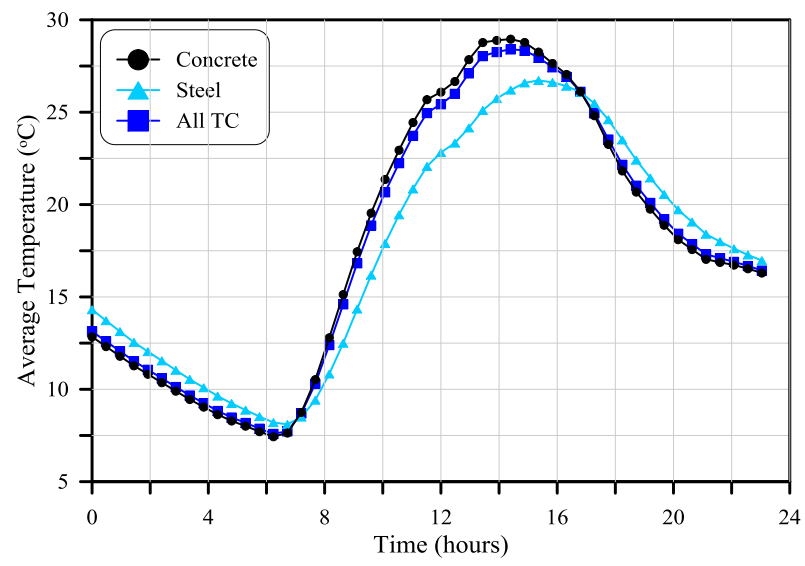

Fig. 12: Hourly concrete, steel, and all thermocouples average temperatures

\section{Vertical and lateral temperature distribu- tions}

Fig. 13 shows the vertical distribution of the temperatures along the vertical centerline of the composite beam which passes through the vertical centerline of web. This distribution was composed using the top surface thermocouple TC1, passing through thermocouples TC2, TC3, TS1, TS2, TS3, and ending at the bottom surface thermocouple TC10. The figure shows that at 1:00 PM, the vertical distribution of temperature is concave right with hotter top surface, which composes a positive temperature gradient. The figure shows that the maximum vertical temperature gradient occurs between the top surface (TC1) and the central point of the beam (TS2). This is attributed to the accumulated thermal energy absorbed by the top surface and conducted to the closet layers within the top flange during the sunny hours of the day before that time, while the interior parts still colder due to the low thermal conductivity of concrete. Oppositely, at 4:00 AM (before sunrise) and 6:00 PM (after sunset), the distribution is concave to the left, which means that the vertical temperature gradient is negative with top surface temperature lower than interior temperatures. This was discussed in the previous sections and is attributed to the effect of convection cooling on the surfaces, while the interior elements lose their reserved heat slowly because of the weak conductivity of concrete.

Fig. 14 shows the lateral temperature distributions along the horizontal centerline of the top flange of the composite beam. Thus, these distributions were constructed using the thermocouples (from south to north) TC4, TC5, TC3, TC6, and TC7. It is shown that before sunrise (at 4:00 AM), the temperature is almost uniform (which can also be noticed in Fig. 13) with slightly higher temperature at the center where the flange-web junction reserves the largest amount of heat. At 6:00 PM (after sunset), the southern edge still slightly hotter than the northern edge, while at 1:00 PM it is obvious 
that a noticeable positive lateral temperature gradient occurs at the southern edge due to the concentration of the low-altitude solar radiation there.

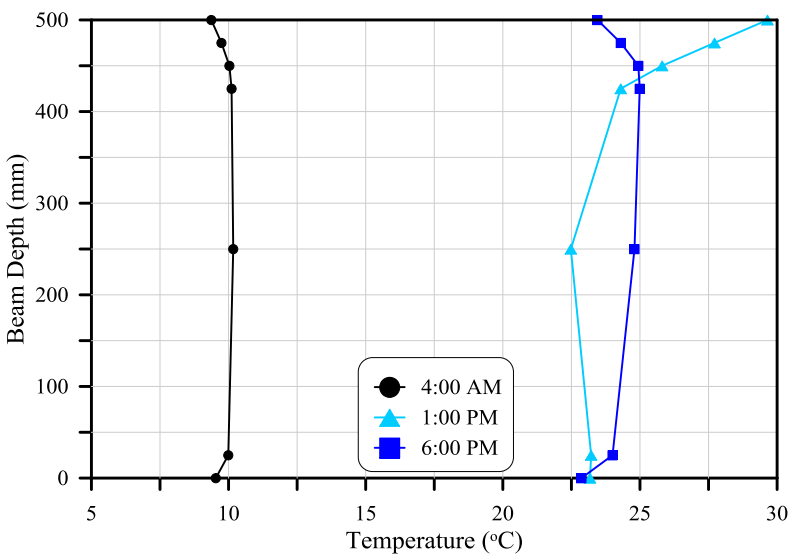

Fig. 13: Vertical temperature distribution at selected time steps

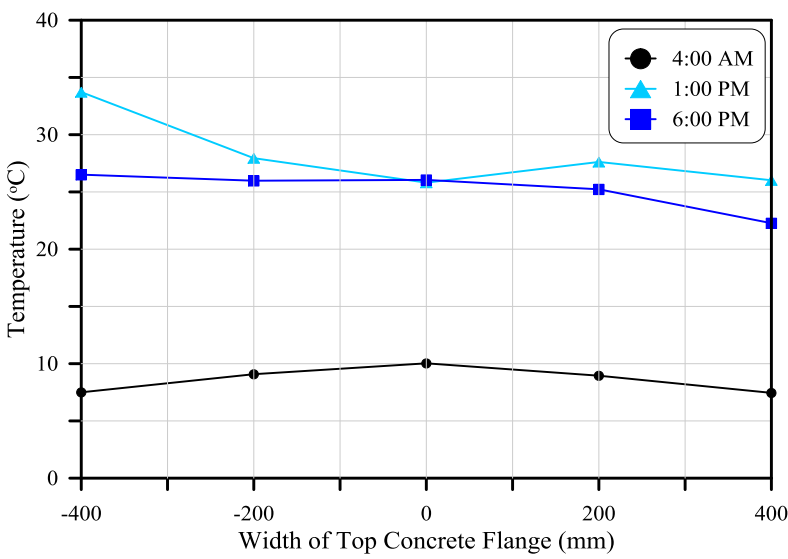

Fig.14: Lateral temperature distributions along the centerline of the top flange at selected time steps

\section{Conclusions}

An I-shape concrete-encased steel beam was constructed in this study to evaluate the effect of solar radiation and air temperature variations of a sunny winter day on temperature distributions in composite beams. Fifteen thermocouples were distributed at different locations along and across the flanges, the web, and the steel section of the composite beam. From the temperature records of the experimental beam, the following conclusion remarks can be drawn: Due to the low altitude of sun rays and because sun moves completely to the south of the equator in winter, the surface thermocouple installed on the southern edge of the top flange exhibited the highest daily temperatures among the fifteen thermocouples.

The hourly variation of temperature of the concrete thermocouples looks like more dependent on the behavior of the air temperaturetime relationship than that of solar radiation along the 24 hours of the investigated day.

For the investigated day with a maximum hourly solar radiation of $712 \mathrm{~W} / \mathrm{m}^{2}$ and daily maximum and minimum air temperatures of 23 and $4.5^{\circ} \mathrm{C}$, the recorded maximum and minimum temperatures of the composite beam were 36.5 and $6.3{ }^{\circ} \mathrm{C}$, respectively, while the maximum difference between hourly maximum and minimum temperatures of the beam was $12.5^{\circ} \mathrm{C}$.

During the hottest hours of the day, positive vertical and lateral temperature gradients form, while the temperature distributions become smoother with minor variations during the cooling hours and especially before sunrise.

\section{References}

[1] Elbadry , M., \& Ghali , A. (1986). Thermal stresses and cracking of concrete bridges. ACI Journal, 83(6), 1001-1009.

[2] Song, Z., Xiao, J., \& Shen, L. (2012). On temperature gradients in high-performance concrete box girder under solar radiation. Advances in Structural Engineering, 15(3), 399-415.

[3] Kromanis, R., \& Kripakaran, P. (2014). Predicting thermal response of bridges using regression models derived from measurement histories. Computers and Structures, 136, 64-77.

[4] Lee, J-H. (2012). Investigation of extreme environmental conditions and design thermal gradients during construction for prestressed concrete bridge girders. Journal of Bridge Engineering, 17(3), 547-56

[5] Tayşi, N., \&Abid ,S. R. (2015). Temperature distributions and variations in concrete box-girder bridges: experimental and finite element parametric studies. Advances in Structural Engineering, 18(4), 469-486.

[6] Abid , S., Tayşi, N., \& Özakça , M. (2016). Experimental analysis of temperature gradients in concrete box girders. Construction and Building Materials, 106, 523-532.

[7] Abid, S. R., Alrebeh, S., Tayşi, N., Özakça, M. (2016). Finite element thermal analysis of deep box-girders. International Journal of Civil Engineering and Technology, 7, 128-139.

[8] Abid, S. R. (2018). Three-dimensional finite element temperature gradient analysis in concrete bridge girders subjected to environmental thermal loads. Cogent Engineering, 5, 1-15.

[9] Liu, H., Chen, Z., \& Zhou, T. (2013). Temperature distribution and structural behavior of box-sectional arch structures under solar radiation. Advanced Steel Construction, 9(4), 298-308.

[10] Wang, Y., Shi, Y., \& Lin, C. (2010). Experimental study on the temperature of steel members in sunshine. Journal of Building Structures, $31,140-147$.

[11] Liu, H., Chen, Z., \& Zhou, T. (2012). Theoretical and experimental study on the temperature distribution of H-shaped steel members under solar radiation. Applied Thermal Engineering, 37, 329-335.

[12] Abid, S. R., Mussa , F., Tayşi, N., \& Özakça, M. (2018). Experimental and finite element investigation of temperature distributions in concrete-encased steel girders. Structural Control and Health Monitoring, 1-23. 